Article

\title{
Conversion of Fructose to HMF in a Continuous Fixed Bed Reactor with Outstanding Selectivity
}

\author{
Eric Weingart, Sarah Tschirner, Linda Teevs and Ulf Prüße *
}

Thuenen Institute of Agricultural Technology, Bundesallee 47, 38116 Braunschweig, Germany; eric.weingart@thuenen.de (E.W.); sarah.tschirner@thuenen.de (S.T.); linda.teevs@thuenen.de (L.T.)

* Correspondence: ulf.pruesse@thuenen.de; Tel.: +49-531-596-4270

Academic Editors: Michela Signoretto and Federica Menegazzo

Received: 28 June 2018; Accepted: 18 July 2018; Published: 20 July 2018

\begin{abstract}
Hydroxymethylfurfural (HMF) is a very promising component for bio-based plastics. Efficient synthesis of HMF from biomass is still challenging because of fast degradation of HMF to by-products under formation conditions. Therefore, different studies, conducted mainly in monophasic and biphasic batch systems with and without water addition have been published and are still under investigation. However, to produce HMF at a large scale, a continuous process is preferable. Until now, only a few studies have been published in this context. In this work, it is shown that fluorous alcohol hexafluoroisopropanol (HFIP) can act as superior reaction solvent for HMF synthesis from fructose in a fixed bed reactor. Very high yields of $76 \%$ HMF can be achieved in this system under optimized conditions, whilst the catalyst is very stable over several days. Such high yields are only described elsewhere with high boiling reaction solvents like dimethylsulfoxide (DMSO), whereas HFIP with a boiling point of $58^{\circ} \mathrm{C}$ is very easy to separate from HMF.
\end{abstract}

Keywords: HMF; continuous fixed bed reactor; heterogeneous catalysis; HFIP; fructose

\section{Introduction}

Renewable resources are promising alternatives to dwindling fossil resources for the production of important platform chemicals. One of the most interesting organic compounds that can be obtained from renewable raw materials is 5-hydroxymethylfurfural (HMF). Because of its versatile functionality, $\mathrm{HMF}$ is an important key intermediate in the production of various bio-based chemicals.

A promising HMF oxidation product is furandicarboxylic acid (FDCA). FDCA is the major building block for polyethylene furanoate (PEF), a bio-based alternative for the important plastic polyethylene terephthalate (PET). The market volume of PET of approx. 50 million t/a illustrates the potential and the importance of HMF. Different monophasic reaction systems like water, DMSO, ionic liquids or biphasic reaction systems in batch mode have been applied for the dehydration of fructose to produce HMF. Promising results with HMF yields and selectivities up to $90 \%$ are achieved using organic solvents or biphasic reaction systems [1-4]. However, in order to produce sufficient quantities of HMF, a continuous production is required. Until today, only a few studies in the field of continuous single phase as well as continuous biphasic systems for HMF production have been carried out. Tuercke et al. [5] used a continuous microreaction process for $\mathrm{HCl}$ catalysed dehydration of aqueous fructose. In this single phase, a fructose conversion of $71 \%$ with an HMF yield of $54 \%$ and a selectivity of $75 \%$ could be achieved. The addition of the co-solvent DMSO led to an increase in HMF selectivity to $85 \%$. Jeong et al. [6] used continuously generated HMF as an intermediate to produce different heterocyclic furan chemicals. They used a functionalized capillary micro reactor for catalytic dehydration of fructose in DMSO. At a reaction temperature of $150{ }^{\circ} \mathrm{C}$ and a reaction time of $6 \mathrm{~min}$, both the conversion and selectivity reached $99 \%$. Schön et al. [7] also used a monophasic continuous 
system for HMF production. With fructose in DMSO as a starting material and quartz sand-based cartridge as a reactor, a reaction temperature of $180^{\circ} \mathrm{C}$ and a flow rate of $0.6 \mathrm{~mL} / \mathrm{min}$, HMF yields of $90.3 \%$ could be achieved. However, the use of DMSO as a solvent is not preferable. Because of its high boiling point $\left(189^{\circ} \mathrm{C}\right)$, the products cannot easily be separated, and DMSO degrades at higher temperatures in acidic reaction systems [8].

A few studies can also be found on the use of biphasic reaction systems for the continuous production of HMF. The biphasic solvent system of a $0.25 \mathrm{M}$ aqueous solution of fructose and methylisobutylketone (MIBK) as the extraction phase led to an HMF yield of 74\% [9]. Using similar systems, Shimanouchi et al. [10] and Lueckgen et al. [11] achieved $88 \%$ yield and 93\% yield, respectively, in the MIBK phase with a fructose solution of $10 \mathrm{wt} \%$. In another system, Muranaka et al. [12] described the formation of HMF in a micro reactor with a yield of $80.9 \%$, using phosphate buffer saline as the reaction phase and 2-sec-butyl phenol (2BP) as the extraction phase.

A disadvantage of all the mentioned research is the use of solvents with high boiling points and the resulting difficult separation of the thermally unstable HMF. Furthermore, the yield of HMF in biphasic systems is the sum of HMF in aqueous and organic phases, which leads to the problem of separating HMF from the catalysts in aqueous phase.

In our previous work $[13,14]$, we showed in a batch system that hexafluoroisopropanol (HFIP, Scheme 1) in combination with water and with the use of an acidic ion exchanger (Lewatit K2420 or Amberlyst 15) is a very well-suited monophasic system for the dehydration of fructose to HMF.<smiles>OC(C(F)(F)F)C(F)(F)F</smiles>

Scheme 1. HFIP structure.

HFIP is characterised by a low boiling point of $58{ }^{\circ} \mathrm{C}$, which leads to low thermal stress for HMF and makes it easy to separate the solvent. In a batch reaction system, we achieved an HMF yield of $76 \%$ at complete conversion of fructose [14]. Therefore, we want to enter the next stage for an industrial process by testing HFIP as a solvent in a continuous fixed bed reactor.

\section{Results and Discussion}

As already mentioned, our preliminary study [14] of the synthesis of HMF from fructose in HFIP with the heterogeneous catalyst Lewatit K2420 in a batch reactor showed a high yield. As consequence of this study, a fixed bed reactor based on Lewatit K2420 as a catalyst bed was designed (see Figure 6 in Section 3.1). A fructose/HFIP/water solution was pumped through the reactor and samples were taken, which resulted in the following reaction course (Figure 1).

In the first sample, after seven minutes, fructose, HMF or the by-products formic acid and levulinic acid are detectable, because the complete feed is adsorbed in the catalyst bed. With increasing time, HMF and the by-products are detected, whilst the fructose concentration is zero. Around $80 \%$ of fructose is converted into HMF and the by-products formic and levulinic acid. The remaining $20 \%$ fructose is expected to be converted into undetectable humins. After a certain time, the HMF and by-product concentrations do not change significantly. Therefore, a steady state is reached, whereby the amount of time for the different compound concentrations to reach the steady state differs. This means that HMF and the by-products interact with the catalyst bed differently, which may be explained by the fact that the acidic by-products and the acidic catalyst bed will repel each other, whereas the neutral HMF will not.

Knowing this behavior, the following different experiments were performed. To ensure reliable results for each change of reaction temperature $\left(95-105^{\circ} \mathrm{C}\right)$ and $\mathrm{H}_{2} \mathrm{O}$ content in HFIP $(12.5-17.5 \mathrm{vol} \%$ $\mathrm{H}_{2} \mathrm{O}$ in HFIP), the average of three samples was calculated, which were taken after a minimum of the triple residence time $\tau$. In all experiments, standard deviations of $<1 \%$ for conversion, yield 
or by-product formation were calculated; therefore, no error bars are shown in the figures. The chosen reaction conditions are based on the optimized conditions of the prior study [14] in a batch reaction system.

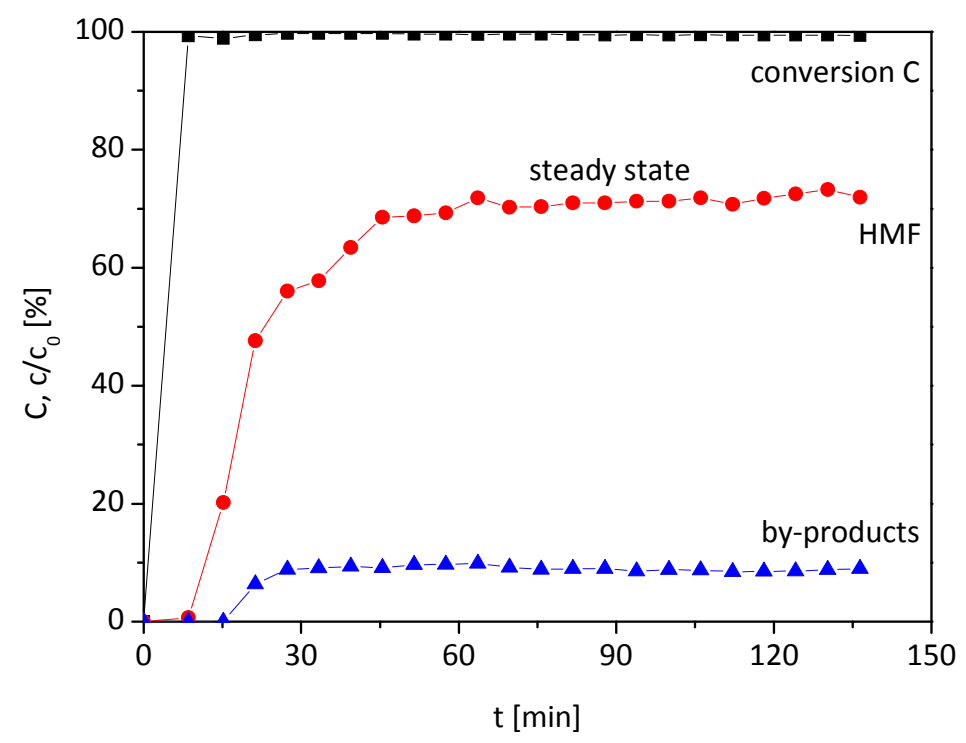

Figure 1. Reaction course in a continuous fixed bed reactor until a steady state was reached $(0.1 \mathrm{M}$ fructose, $105{ }^{\circ} \mathrm{C}, 15 \mathrm{vol} \% \mathrm{H}_{2} \mathrm{O}$ in HFIP, residence time $\tau=20 \mathrm{~min}, 1.7 \mathrm{~g}$ Lewatit $\mathrm{K} 2420$ catalyst bed).

At first, the temperature of the catalyst bed was adjusted to $95{ }^{\circ} \mathrm{C}$, and the water content of the reaction solution was varied in the range of $12.5-17.5 \mathrm{vol} \%$ (Figure 2).

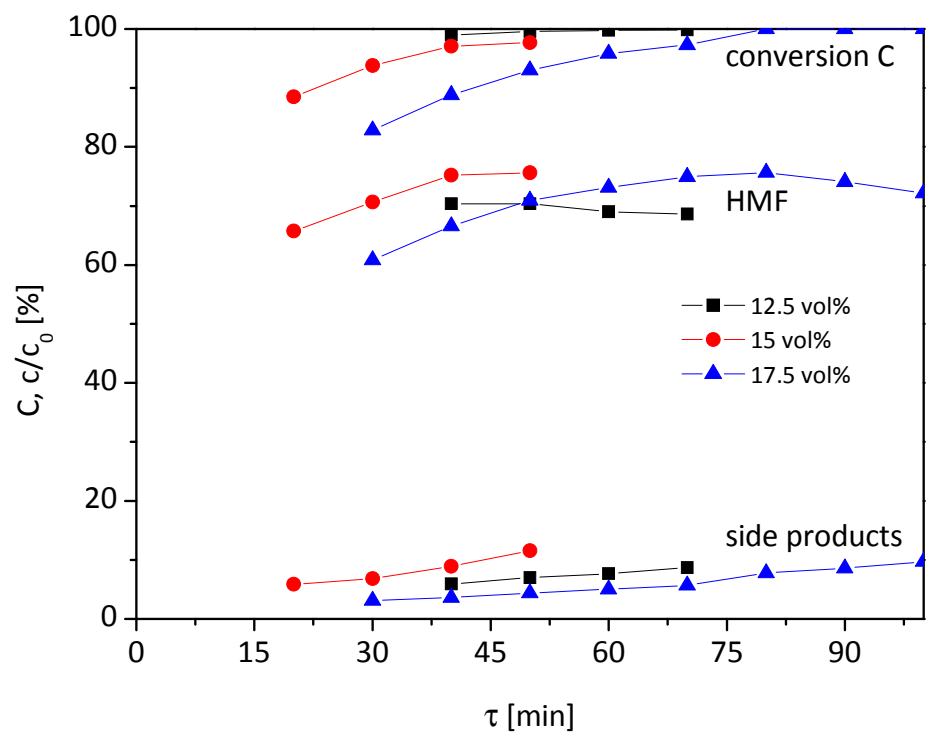

Figure 2. Influence of water content on conversion, HMF yield and by-products $\left(0.1 \mathrm{M}\right.$ fructose, $95{ }^{\circ} \mathrm{C}$, $12.5-17.5 \mathrm{vol} \% \mathrm{H}_{2} \mathrm{O}$ in HFIP, $1.7 \mathrm{~g}$ Lewatit $\mathrm{K} 2420$ catalyst bed).

At a water content of $12.5 \mathrm{vol} \%$ (black squares), the complete conversion of fructose is observed for all tested $\tau$ higher than $40 \mathrm{~min}$. The course of the graph of HMF is the reverse. For $\tau=40 \mathrm{~min}$ the highest HMF yield of $70 \%$ is observed, which drops slightly to $68 \%$ at higher $\tau$. Also, the by-products are formed at higher rates from 5 to $11 \%$ with rising residence time. In sum, the course of the graphs are only slightly influenced by residence time at a water content of $12.5 \mathrm{vol} \%$. If the water content 
is raised to 15 or $17.5 \mathrm{vol} \%$, the influence of the residence time on conversion and yield increases. At $15 \mathrm{vol} \%$ (red circles), the HMF yield enhances gradually from 66 to $75 \%$ and conversion from 88 to $97 \%$ when the residence time is extended from 20 to $40 \mathrm{~min}$. Further extension of the residence time to $50 \mathrm{~min}$ has no effect on the HMF yield, only the conversion and by-product formation increase. However, the variation of $\tau$ has no effect on the selectivity which remains around $75 \%$.

For the $17.5 \mathrm{vol} \%$ water content (blue triangles), the course of the graph is similar to $15 \mathrm{vol} \%$. At the low residence time of $30 \mathrm{~min}$, a conversion rate of $83 \%$ is reached, with $61 \% \mathrm{HMF}$ yield and $3 \%$ yield of by-products. When extending $\tau$ to $80 \mathrm{~min}$, a full conversion and maximum HMF yield of $76 \%$ are achieved, whilst $8 \%$ by-products are formed. With further prolonging of $\tau$, the yield of HMF drops again and by-product formation increases, which lowers the selectivity.

So all in all, the highest HMF yield of around $75 \%$ is achieved with a water content of 15 or $17.5 \mathrm{vol} \%$ and when the residence time is adjusted accordingly. Below $15 \mathrm{vol} \%$ water content, only $70 \%$ HMF yield can be achieved at $95^{\circ} \mathrm{C}$. The selectivity does not change significantly by variation of residence time when fructose is not completely converted for all three tested water contents.

In Figure 3, the graphs of the reaction solutions with a $12.5-17.5 \mathrm{vol} \%$ water content at a higher reaction temperature of $100{ }^{\circ} \mathrm{C}$ are shown. Due to the higher temperature, shorter residence times were chosen compared to the reaction at $95^{\circ} \mathrm{C}$ (Figure 2).

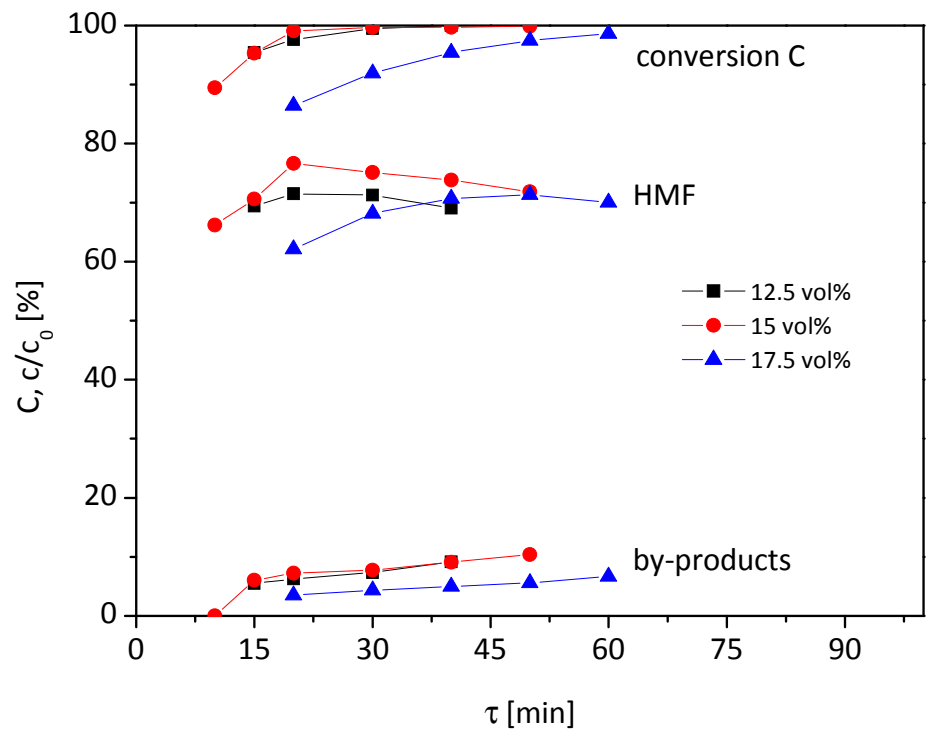

Figure 3. Influence of water content on conversion, HMF yield and by-products $\left(0.1 \mathrm{M}\right.$ fructose, $100{ }^{\circ} \mathrm{C}$, 12.5-17.5 vol\% $\mathrm{H}_{2} \mathrm{O}$ in HFIP, $1.7 \mathrm{~g}$ Lewatit K2420 catalyst bed).

For the $12.5 \mathrm{vol} \%$ water content, the graphs at $100{ }^{\circ} \mathrm{C}$ show similarities to the graphs at $95{ }^{\circ} \mathrm{C}$. The HMF yield rises with increasing residence time to approx. $70 \%$ at $20 \mathrm{~min}$ with a high conversion rate and decreases again when the residence time exceeds $20 \mathrm{~min}$. However, the graphs are only slightly affected by residence time. If the water content is increased to $15 \mathrm{vol} \%$, the graphs have a similar course in the case of conversion and by-product formation, but differ in HMF yield. Compared to the graph at $12.5 \mathrm{vol} \%$, a higher maximum in HMF yield of $76 \%$ can be achieved at $20 \mathrm{~min}$ residence time. At a lower or higher residence time, the HMF yield drops again.

When the water content is $17.5 \mathrm{vol} \%$, an HMF yield of $62 \%$ at $86 \%$ conversion and $20 \mathrm{~min}$ residence time is reached. With rising residence time, the HMF yield increases to $71 \%$ at $50 \mathrm{~min}$ residence time with $97 \%$ conversion. The selectivity does not change in this period significantly and remains at $72-73 \%$. A further increase of $\tau$ reduces the yield of HMF again.

As a last step, the temperature was increased to $105^{\circ} \mathrm{C}$ (Figure 4). Unlike the reaction at $95^{\circ} \mathrm{C}$ and $100{ }^{\circ} \mathrm{C}$, the conversion, yield and by-product formation only slightly changed by varying the 
residence time. The highest HMF yield of $73 \%$ is achieved with 15 and $17.5 \mathrm{vol} \%$ water content at 20 min residence time.

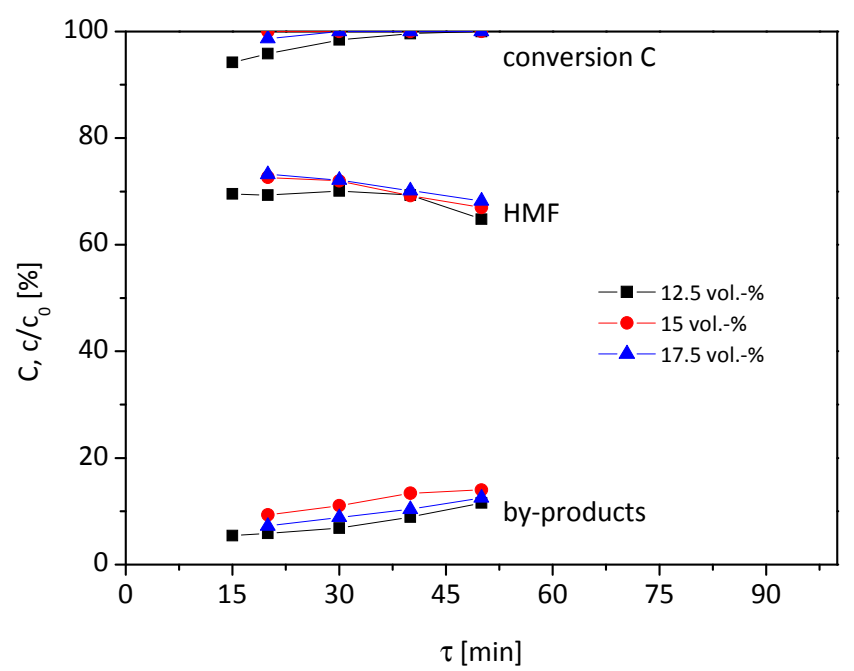

Figure 4. Influence of water content on conversion, HMF yield and by-products $\left(0.1 \mathrm{M}\right.$ fructose, $105{ }^{\circ} \mathrm{C}$, $12.5-17.5 \mathrm{vol} \% \mathrm{H}_{2} \mathrm{O}$ in HFIP, $1.7 \mathrm{~g}$ Lewatit K2420 catalyst bed).

In sum, the maximum yield of HMF ranges between $70-76 \%$ for all tested water concentrations (12.5-17.5 vol\%) and reaction temperatures $\left(95-105^{\circ} \mathrm{C}\right)$. Those belong to the highest yields of HMF reported in heterogeneous continuous reaction systems without using high boiling solvents or harsh reaction conditions ( $\mathrm{T}>110^{\circ} \mathrm{C}$, mineral acids) [1]. The highest $\mathrm{HMF}$ yield of $76 \%$ is achieved when using $17.5 \mathrm{vol} \%$ water content at $95^{\circ} \mathrm{C}$ and $\tau=80 \mathrm{~min}(0.162 \mathrm{~mL} / \mathrm{min})$ or $15 \mathrm{vol} \%$ water content at $100{ }^{\circ} \mathrm{C}$ and $\tau=20 \mathrm{~min}(0.588 \mathrm{~mL} / \mathrm{min})$. These result in a space time yield of $7.6 \times 10^{-5} \mathrm{~mol} /(\mathrm{L} \mathrm{min})$, which is better than in other tested continuous processes [15], even with hard-to-separate DMSO or ionic liquids.

If the reaction is carried out under incomplete conversion of fructose, the selectivity of the process is not influenced by residence time in the investigated range. Further research has to be done to determine the reaction kinetics in order to explain this behaviour. The balance of all experiments cannot be completely explained by HPLC analysis. Therefore, the non-detected amount of $10-20 \%$ is expected to be humins, that are dissolved in the reaction solution and/or adsorbed at the catalyst surface.

In the following experiment, the catalyst long-term stability over several days was evaluated. The best reaction conditions based on prior experiments were chosen: $95{ }^{\circ} \mathrm{C}$ and $17.5 \mathrm{vol} \%$ water content at a residence time of $80 \mathrm{~min}$ (Figure 5). For this experiment, three samples every six hours were taken (standard derivation of $<1 \%$ for conversion, yield and by-products).

During the first hours, the yield of HMF increases from 74 to $80 \%$ at nearly complete conversion. After 8.7 days, the yield and conversion decrease gradually over time to $70 \%$ and $95 \%$, respectively. During this time the selectivity of the HMF formation drops from 80 to $74 \%$, which implies that the selectivity is less influenced by catalyst deactivation than the yield of HMF. The integration of the HMF curve equals an overall yield of $26.6 \mathrm{~g}$ or $74 \% \mathrm{HMF}$ in those 8.7 days. The balance drops over time as well, which may be explained by adsorbed humins on the catalyst surface, which can react with HMF because of reactive functional groups. It is also conceivable that the catalyst pores become clogged by adsorbed humins, which worsens the active site accessibility and diffusion in and out of the pores. Also, leaching of acid sites is possible.

Because the influence of the flow rate on film thickness on the catalyst surface is of major impact for diffusion limitation in future work, the influence of the flow rate will be tested. It is expected that a much higher flow rate may be beneficial for HMF yield at same conversion, as a faster diffusion of 
HMF out of the particles will reduce the possibility of side reactions. This can be attained by higher flow rates using a longer catalyst bed to achieve the same residence times.

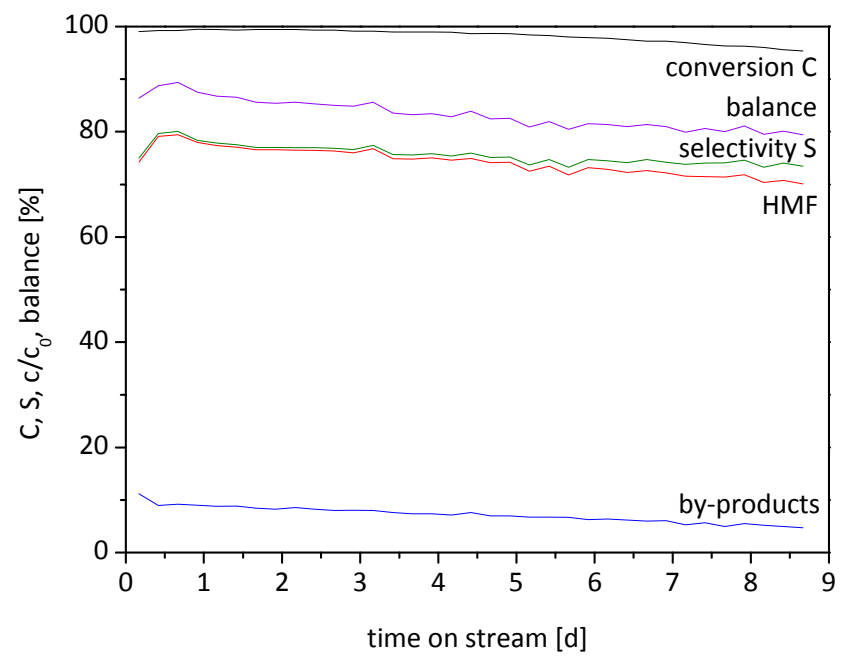

Figure 5. Long-term stability of the fixed bed $\left(\tau=80 \mathrm{~min}(0.162 \mathrm{~mL} / \mathrm{min}), 0.1 \mathrm{M}\right.$ Fructose, $95^{\circ} \mathrm{C}$, $17.5 \mathrm{vol} \% \mathrm{H}_{2} \mathrm{O}$ in HFIP, $1.7 \mathrm{~g}$ Lewatit $\mathrm{K} 2420$ catalyst bed).

\section{Materials and Methods}

\subsection{Reactor Setup}

The fixed bed reactor (Figure 6) embedded in the reactor oven (HTM-Reetz LK 500-40-400-1, Berlin, Germany) consists of a $15 \mathrm{~cm} \times 0.95 \mathrm{~cm}$ (inner diameter) stainless steel tube (technical useful volume $6 \mathrm{~mL}$ ), a catalyst bed of $1.7 \mathrm{~g}$ Lewatit K2420 (dry matter, measured by Ohaus MB45, Parsippani, NJ, USA), which is fixated by glass wool at the outlet and a frit at the inlet, as well as a Pt100 thermistor in the middle of the bed. The feed consisting of HFIP, fructose and water is pumped via an HPLC-pump (Knauer Smartline Pump 100, Berlin, Germany) through a $0.16 \mathrm{~cm}$ (inner diameter) PTFE pipe into the fixed bed reactor. At the reactor outlet, a $50 \mathrm{~cm} \times 0.16 \mathrm{~cm}$ (inner diameter) PTFE pipe is connected, which acts as a cooling zone. To avoid vaporization of reaction solution, a pressure valve (Swagelok KCB Series, Solon, OH, USA) at the end of the cooling zone keeps the complete reactor setup at 20 bar pressure. Samples were taken with an autosampler (HiTec Zang, AutoSam 360, Herzogenrath, Germany) after the pressure valve.

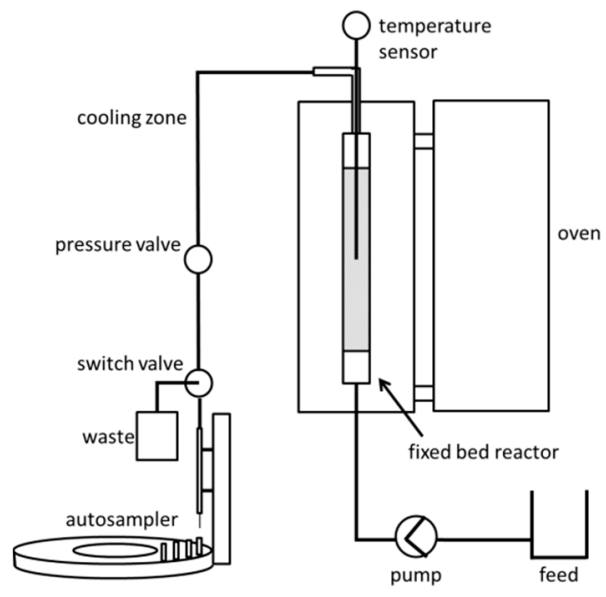

Figure 6. Fixed bed reactor setup. 
The mean residence time in the reactor was calculated by the pulse method. A small amount of aqueous $\mathrm{H}_{2} \mathrm{SO}_{4}$ was pumped at different volume flow rates of pure water through the reactor whilst measuring the $\mathrm{pH}$ (Schott Instruments Lab860, Mainz, Germany with Mettler Toledo InLab Micro probe, Columbus, OH, USA) of the reactor outlet stream constantly.

\subsection{HMF-Synthesis}

Before starting the experiment, water was pumped through the heated reactor until the desired temperature $\left(95-105^{\circ} \mathrm{C}\right)$ was reached. Then, the feed was switched to the reaction solution consisting of $0.1 \mathrm{M}$ fructose in the desired ratio of HFIP/water mixture (12.5-17.5 vol\% water in HFIP). Three samples were taken after triple mean residence time. The standard deviations between all sets of samples were $<1 \%$ in terms of conversion, yield of HMF and yield of by-products.

\subsection{Materials}

The following chemicals were used as received: Fructose $(99.5 \%$ p.a. Carl Roth, Karlsruhe, Germany), HFIP (99\%, Apollo Scientific, Bredbury, UK, 99\% Flurochem, Hadfield, UK), water (Merck Milli-Q, Darmstadt, Germany), Lewatit K2420 (Lanxess, Cologne, Germany), levulinic acid (98\%, Merck, Darmstadt, Germany), formic acid (98\%, Carl Roth, Karlsruhe, Germany), HMF (98\%, Sigma-Aldrich, St. Louis, MO, USA). Lewatit K2420 was washed with water until the permeate was colourless and was stored in water prior to use. HFIP was recycled by atmospheric evaporation distillation (bp. $58^{\circ} \mathrm{C}$ ) where no HFIP was detectable by HPLC in the remaining aqueous solution.

\subsection{Methods}

Quantitative analysis was performed with a Shimadzu HPLC (Kyoto, Japan) with Bio-Rad Animex HPX-87H column (Hercules, CA, USA) at $60{ }^{\circ} \mathrm{C}, 0.7 \mathrm{~mL} / \mathrm{min}$ flow rate of $5 \mathrm{mM} \mathrm{H}_{2} \mathrm{SO}_{4}$ and refraction index detector and UV detector at $210 \mathrm{~nm}$. Calibration was realised with external standards. All samples were diluted by a ratio of at least 1:10 with water (Merck Milli-Q) prior to analysis.

\section{Conclusions}

The flourous alcohol hexafluoroisopropanol shows superior performance for HMF synthesis from fructose catalysed by strong acidic ion exchange resin using a Lewatit K2420 in a continuous fixed bed reactor. Compared to previous batch experiments [14] the HMF yield is comparable (76\% batch vs. $76 \%$ fixed-bed). Therefore, the transfer from batch process to continuous process was entirely successful.

Compared to the literature [5-7,9-12,15], the essential advantage is the use of the easy-to-separate solvent HFIP in a continuous fixed bed reactor system without using hard-to-separate high boiling solvents, homogeneous catalysts or phase modifiers. At the same time, yield and productivity of HMF are of a similar or even higher level.

Author Contributions: E.W., L.T. and U.P. conceived and designed the experiments, E.W. and S.T. performed the experiments, analyzed and discussed the data, E.W., S.T., L.T. and U.P. wrote the paper.

Funding: This research is funded by the German Federal Ministry of Food and Agriculture, following a decision of the German Bundestag, via the Agency of Renewable Resources (Grant No. 22003813).

Conflicts of Interest: The authors declare no conflict of interest.

\section{References}

1. Van Putten, R.J.; van der Waal, J.C.; de Jong, E.; Rasrendra, C.B.; Heeres, H.J.; de Vries, J.G. Hydroxymethylfurfural, a versatile platform chemical made from renewable resources. Chem. Rev. 2013, 113, 1499-1597. [CrossRef] [PubMed]

2. Teong, S.P.; Yi, G.; Zhang, Y. Hydroxymethylfurfural production from bioresources: Past, present and future. Green Chem. 2014, 16, 2015-2026. [CrossRef] 
3. Weingart, E.; Teevs, L.; Krieg, R.; Prüße, U. Hexafluoroisopropanol as a Low-Boiling Extraction Solvent for 5-Hydroxymethylfurfural Production. Energy Technol. 2018, 6, 432-440. [CrossRef]

4. Román-Leshkov, Y.; Chheda, J.N.; Dumesic, J.A. Phase modifiers promote efficient production of hydroxymethylfurfural from fructose. Science 2006, 312, 1933-1937. [CrossRef] [PubMed]

5. Tuercke, T.; Panic, S.; Loebbecke, S. Microreactor Process for the Optimized Synthesis of 5-Hydroxymethylfurfural: A Promising Building Block Obtained by Catalytic Dehydration of Fructose. Chem. Eng. Technol. 2009, 32, 1815-1822. [CrossRef]

6. Jeong, G.-Y.; Singh, A.K.; Sharma, S.; Gyak, K.W.; Maurya, R.A.; Kim, D.-P. One-flow syntheses of diverse heterocyclic furan chemicals directly from fructose via tandem transformation platform. NPG Asia Mater. 2015, 7, e173. [CrossRef]

7. Schön, M.; Schnurch, M.; Mihovilovic, M.D. Application of continuous flow and alternative energy devices for 5-hydroxymethylfurfural production. Mol. Divers. 2011, 15, 639-643. [CrossRef] [PubMed]

8. Oda, R.; Hayashi, Y. Some Researches on the Chemistry of Dimethyl Sulfoxide and Related Compounds. Bull. Inst. Chem. Res. 1969, 47, 480-521.

9. Brasholz, M.; von Kanel, K.; Hornung, C.H.; Saubern, S.; Tsanaktsidis, J. Highly efficient dehydration of carbohydrates to 5-(chloromethyl)furfural (CMF), 5-(hydroxymethyl)furfural (HMF) and levulinic acid by biphasic continuous flow processing. Green Chem. 2011, 13, 1114-1117. [CrossRef]

10. Shimanouchi, T.; Kataoka, Y.; Tanifuji, T.; Kimura, Y.; Fujioka, S.; Terasaka, K. Chemical conversion and liquid-liquid extraction of 5-hydroxymethylfurfural from fructose by slug flow microreactor. AIChE J. 2016, 62, 2135-2143. [CrossRef]

11. Lueckgen, J.; Vanoye, L.; Philippe, R.; Eternot, M.; Fongarland, P.; de Bellefon, C.; Favre-Réguillon, A. Simple and selective conversion of fructose into HMF using extractive-reaction process in microreactor. J. Flow Chem. 2018, 8, 3-9.

12. Muranaka, Y.; Nakagawa, H.; Masaki, R.; Maki, T.; Mae, K. Continuous 5-Hydroxymethylfurfural Production from Monosaccharides in a Microreactor. Ind. Eng. Chem. Res. 2017, 56, 10998-11005. [CrossRef]

13. Vorlop, K.-D.; Prüße, U.; Krieg, R.; Teevs, L. Improved 5-Hydroxymethylfurfural Production Using a Multi-Fluorinated Alcohol Compound. U.S. Patent 10,005,748, 26 June 2018.

14. Tschirner, S.; Weingart, E.; Teevs, L.; Prüße, U. Catalytical dehydration of fructose to 5-HMF in HFIP. Molecules 2018. submitted.

15. Aellig, C.; Hermans, I. Continuous D-fructose dehydration to 5-hydroxymethylfurfural under mild conditions. ChemSusChem 2012, 5, 1737-1742. [CrossRef] [PubMed]

Sample Availability: Samples of the compound HMF are available from the authors.

(C) 2018 by the authors. Licensee MDPI, Basel, Switzerland. This article is an open access article distributed under the terms and conditions of the Creative Commons Attribution (CC BY) license (http:/ / creativecommons.org/licenses/by/4.0/). 